\title{
Two Sides of the Same Coin: Finding Common Roots in Husserlian Phenomenology and Freudian Psychoanalysis
}

\author{
Manali Arora, Master's Student, Ambedkar University Delhi, India \\ Email: manaliarora487@gmail.com
}

\begin{abstract}
Phenomenology and psychoanalysis, two of the most prominent accounts of subjectivity, may, at first, appear as if they are opposites, but the impression that phenomenology and psychoanalysis are antithetical can be transformed when both the frameworks are looked at closely enough. Divergences between psychoanalysis and phenomenology have concealed, profound agreement in the subject matter, approach, and methods of these two schools of psychology. Therefore, the aim of this paper is to refurbish and elaborate a preliminary outline of conceptual correspondences between Husserl's Phenomenology and Freud's Psychoanalysis. Elucidating the convergences of Psychoanalysis with Husserl's well-developed phenomenological tradition can be of immense potential salience to psychoanalysts and the anthropological analyses of subjectivity. In exploring how Husserl's rendering of psychology enhances or alters our understanding of Psychoanalysis, we encounter this dialogue unfolding.
\end{abstract}

Keywords: Husserl's Phenomenology, Freud's Psychoanalysis, Convergence, Conceptual Correspondences

\section{INTRODUCTION}

"Scientific points of view, according to which my existence is a moment of the world's, are always both naïve and at the same time dishonest, because they take for granted, without 
explicitly mentioning it, the other point of view, namely that of consciousness, through which from the outset a world forms itself around me and begins to exist for me."

-Merleau Ponty, 1945/1962

From a historical perspective, Edmund Gustav Albrecht Husserl, principal founder of phenomenology, and Sigmund Freud, founder of Psychoanalysis, were contemporaries. The first thorough psychoanalytic work and the first phenomenological work were published simultaneously; Freud's The interpretation of dreams, published in 1900, and Husserl's Logical investigations, published in two volumes in 1900-1901 (Karlsson, 2010). Freud and Husserl, both attended lectures given by the philosopher Franz Brentano (1838-1917), whose influence on Husserl is apparently significant, while his influence on Freud is unclear but probably subtle (Cohen, 2000). From there, both psychoanalysis and phenomenology advanced into movements with different branches.

Superficially, psychoanalysis and phenomenology do not seem to have much to do with each other (Wertz, 1993). Phenomenology, concerned with studying consciousness as immediately given, whereas psychoanalysis with its aim to investigate the unconscious, which Freud has described using a well-known metaphor, 'the tip of an ice-berg,' using tremendously sophisticated methods, is outwardly suggestive of their aspirations pointing at diverging directions, seeming to have nothing in common (Spiegelberg, 1972). However, our understanding of it being so changes considering the dependence of psychoanalytic practice on consciousness (Karlsson, 2010). According to Hartmann (1964) and Lagache (1963), the investigation of ego in psychoanalysis requires a "return from hypothetical constructions and a closeness to the givens of everyday experience," an essential condition of psychoanalysis, bringing it closer to phenomenology. As Csordas (2012) suggests, a dialogue between them is 
both inevitable and necessary, and sifting through the differences to the points of convergences, we see this dialogue opening out.

\section{Freudian Psychoanalysis}

Sigmund Freud, the founder of psychoanalysis, developed this theory based on the development of the physical science of that time, which has now undergone many refinements under the influence of modern science (Sibi, 2020). In psychoanalysis, it is accepted that something has been understood when the discourse about it is inciting (Csordas, 2012). "Elusiveness and ambiguity" are not only acceptable, but they might also be crucial in depicting the "complexity of human experience accurately," says Fonagy (2003). What makes this perspective unique is its freedom from constraint and pressing emphasis on subjectivity.

To Gerson (2017), something as complex and elastic as the psychoanalytic theory, accepts the patient for whom s/he is, rather than comparing them to some "norm." Gerson (2017) further adds that the patient, rather than being "pigeon-holed into some pre-determined diagnostic category," is seen as encompassing her or his own set of unique experiences. Psychoanalytical therapy is not time-bound; it rather "affords the patient the dignity and respect" to move along the process of therapy and to maintain the therapeutic alliance, in a pace most suitable and for as long as it "proves valuable" (Gerson, 2017).

In psychoanalysis, the patient chooses to either "cling to their private opinion" or place her/his self in the hands of a physician, supposedly a "wise mediator between the private and the communal world, between deception and truth" (Binswanger 1963). In the therapeutic process, the aim is not to alleviate the patient's feelings, wishes and hopes but to assist them move out from the "sphere of despair and descent" to that of ascendence and progress by "reclaiming objectivity in subjectivity" through transference (Csordas, 2012). According to Binswanger (1963), Psychoanalysis deals with a subjective truth rather than an objective one, "with the 
'innermost passion' by virtue of which subjectivity must work itself through objectivity and out of it again" (Binswanger 1963).

According to Boss (1963), Freud emphasized man's existence as a "free, lucid realm into which something can unveil itself and shine forth out of the dark." This implicit insight, Boss (1963) explains is seen in Freud's requirement that patients lie down during the treatment which would allow them to be at ease physically with all limbs horizontally placed, on an equal level. Such was insisted to counteract self-assertion and form a space where the patient can be "totally delivered up to himself" so that infantile impulses make appearances in an absolute openness without possibly being obstructed by face-to-face adult relationship. Csordas (2012) adds that affirmed by such freedom and openness, the relation between analyst and patient becomes a practically illimitable "playground" where all the knowable patient's possibilities for relating is revealed. The analyst, appearing as a "glassy and cold mirror," is in fact thoughtful of the patient's uniqueness and cautious of hindering her or his freedom. Freud emphasised the stance that psychoanalyst is not to "intervene" care but "anticipate" care based on being silently "ahead of the patient in his existential unfolding" in order for him to become "transparent to himself and free for his existence." (Boss 1963)

\section{Husserlian Phenomenology}

Phenomenology, a philosophical movement, originated from the works of the philosopher and mathematician Edmund Husserl, is a philosophy of subjectivity and consciousness. (Karlsson, 2010). The objective of phenomenology is to study the meaning/ essence of a phenomenon and provides a foothold into predicaments of philosophy, from ones in philosophical logic, metaphysics, ontology to ones about the nature of mind (Kelly, 2002). The concept 'phenomenology' contains two terms: 'phenomenon,' which means that which appears/that which shows itself, rather than as it may or may not be in reality (Bakewell, 
2017), and 'logy,' which is translated as structure/law/essence. According to Karlsson (2010), Phenomenology studies the logos of phenomenon - the conditions presupposed for it to be the phenomenon that it is or is experienced to be. The goal to describe the essence of a phenomenon has to do with identifying and clarifying the requisite conditions for it to be what it is. Requisite conditions mean the ones that are required for the subjective experience. Moreover, Karlsson (2010) adds, each particular experience involves both a contingency, i.e., a particularity - and a principal structure, its eidos or essence and in that particular experience, there is a 'grasping' of a necessary, principal structure that is necessary in order for something to be what it is.

The initial aim of Husserl for his phenomenology was for it to be a reflective philosophical discipline that would provide a conceptual underpinning for the different sciences and scholarly disciplines, which would include psychology (Ashworth \& Chung, 2010). The relevance of his work was not to be limited to the study of certain philosophical questions but to work as an epistemological foundation for other disciplines (Karlsson, 2010). According to Ashworth and Chung (2010), this was to be done by clarifying the essential structures of experience which distinguish one discipline from another and regulate the nature of each discipline's concepts. Thus, the aim of his original philosophical project was that Phenomenology was to be philosophy as a rigorous science that would give a foundation to the concepts of each scholarly discipline. (Ashworth \& Chung, 2010)

\section{Conceptual correspondences}

Beginning with the overt goal of each of these intellectual movements, as commonly known, is that Husserl's Phenomenology is descriptive in nature and describes the phenomena, which includes everything that exists or can possibly exist. Psychoanalysis, on the other hand, is therapeutic, as what it seeks to manage are pathologies which include "conditions of 
developmental frustration or emotional distress" (Csordas, 2012). However, in the psychoanalytical therapy, the descriptive nature of phenomenology, of being able to describe the phenomenon, is something that plays out in analyst's understanding of analysand's account of experience, analysand's experience of her emotional state, and the experience of the therapy as being produced by the presence of the analyst and the analysand.

The foremost tenet of Husserl's phenomenology- intentionality entails the general characterization of consciousness as intentional. It refers to the idea that to be aware is necessarily to be aware of something, that consciousness is a consciousness of something (Kung, Smith, \& McIntyre, 1988). Intentionality has to do with meaning, the meaning bestowing of something (Karlsson, 2010). It can be seen that meaning is also central to psychoanalysis as it being concerned with "the pathological, distorted, illogical, that which appears meaningless," from the presupposition that it has meaning (Karlsson, 2010). However, intentionality is a concept not merely limited to the specific intention associated with an action but a kind of tension in relation to the world. There is a "tropism implicit in intentionality, but a kind related to an inherent vitality rather than an autonomic response" (Csordas, 2012). The drive, contrarily, is premised on biological instinct. Csordas (2012) further says that it is a "genetic rather than an existential characteristic of humans." This point of view of the drive energy presupposes an "objectification of the human being”, as MerleauPonty (1982-83) states.

In phenomenology, of importance is the notion of the horizon, which is a flexible limit that depending on a person's location and viewpoint is continuously accommodated as per the person's movement in the world. "It is always in principle possible to find out what is on the other side of the horizon" (Csordas, 2012). Looking at Psychoanalysis, arriving "to the other side" is prevented by the defenses. Defense does not readjust itself with the movements of the person. Although the horizon is "an intrinsic part of the world's structure," the defense is a 
mechanism, "an artifice constructed and self-imposed on the psyche" (Csordas, 2012). Hence, reaching "the other side" becomes difficult in the absence of psychoanalytic intervention.

Husserl's concept of the lifeworld is to turn to the way things are actually lived and experienced in the context and situation in which they occur. When an experience of a phenomenon is investigated, it is to be done via real-life examples in which the phenomenon or experience is embedded rather than asking a set of questions pertaining to specific isolated aspects of the phenomenon which are removed from the whole context in which these aspects were experienced (Ashworth \& Chung, 2010). Similarly, the data through which psychoanalysis grasps meaning are descriptions of the phenomenon itself in its plain visibility, the individual's speech, personal life circumstances, and the cultural milieu (Freud \& Strachey, 1976). All these data are relevant and necessary because, for Freud as well, meaning by its very nature rests not in an isolated event but in the interrelations of different constituents of mental life (Wertz, 1993).

A key concept for phenomenology concerning sociality is intersubjectivity. Each of us has our own personal experiences based on our personal history and individual characteristics, which is the intrasubjective experience. However, to understand and relate to each other, we must be able to extend beyond our own intrasubjective experience to a level of intersubjectivity. Relating at the intersubjective level requires removing own personal details and relating to another's experience in a more "generalized human" manner. (Ashworth \& Chung, 2010). Though psychoanalysis does not foreground a general concept identical to intersubjectivity, it does place a significant emphasis on specific experientially salient forms of intersubjectivity. According to Karlsson (2010), critical components of intersubjectivity are transference and countertransference between analyst and analysand, object relation's 
description of the unconscious grounds of intersubjectivity among significant others, and projection- an example of distorted intersubjectivity in the ego's social environ.

The Husserlian notion of pre-reflective self-consciousness emphasizes that most of our experiences do not occur in the realm of what we know we are doing, feeling, or thinking. We respond to the world before reflecting upon it, and the reflections we do make are ultimately only a tiny portion of the actual experiences of or responses to the world (Ashworth \& Chung, 2010). In contrast, pre-reflective self-consciousness is pre-reflective in that it is an awareness we have before we do any reflecting on our experience. It is an implicit or first-order awareness rather than an explicit or higher-order form of self-consciousness (Gallagher et al., 2019). Bringing this concept in Psychoanalytical therapy, urging the patient to explain "what happened" lets her/him inform the analyst about the experience from a complete human capacity of pre-reflective responding rather than a limited domain of reflection (Ashworth \& Chung, 2010). Allowing the patient to "tell it like it happened" and not redefine the event for the sake of the analyst can help to discover things that could not have been foreseen, adds Ashworth \& Chung (2010). Pre-reflective self-consciousness is not just an added quality to the experience; it constitutes the very mode of being of the experience, as Jean-Paul Sartre (1943) writes.

Looking at Phenomenology from a somewhat superficial perspective, as it's being based on a stereotype, is that phenomenology is "always beginning" (Csordas, 2012). Csordas (2012) adds that phenomenological work is believed to spend much time explicating their theoretical orientation and methodological concepts that the actual work of analysis never happens. Psychoanalysis, similarly is stereotyped as never-ending because of its often-years-long process of treatment. Nonetheless, points Csordas (2012), both these intellectual frames have a common basis in the nature of human experience, which is the "open-ended character of life" that lets one to comprehend "stillness not as peace but as constant movement and 
change." To Csordas (2012), the elements of existence in phenomenology are generally seen 'as a given' or "nonthematized", while for psychoanalysis, the contents of the unconscious are usually "hidden or inaccessible." They comprise different styles of approaching the meaning of being human, and the methods employed are ultimately to bring these contents to disclosure.

To describe something phenomenologically, one should set aside both the "abstract supposition and any intrusive emotional association" by a process called epoche or phenomenological reduction (Bakewell, 2017). It is described as bracketing, suspension of the world of everyday life in order to condense a phenomenon to its "unencumbered essence" (Csordas, 2012). In its application to Psychoanalysis, given the exceptional emphasis, psychoanalysis places on certain concepts like early childhood experiences, how much of these categories can be bracketed out is questionable. Even if it is possible to bracket such conceptual categories (like childhood experience) entirely, the question that comes up is whether we want to give up a category altogether. Implementation of bracketing as a concept in an experience can have its limits, and its application in a clinical setting, although extremely important and beneficial, might be restricted by some of the other conceptual categories. Absolute suspension can be challenging to work with because categories are, as much an aid, as they are obstacles. Working with categories like childhood experience can be suggestive of causation, which phenomenology opposes, but how feasible or even beneficial it is to work without any causation is subject to question. Nevertheless, though categories and causation are to some extent needed, at the same time, an attempt should always be made to be able to see beyond the categories.

Like how epoche and reduction are given a privileged place in Phenomenology, psychoanalysis gives a privileged position to dream interpretation, in that nothing is seen as it being limited to what is visible on the surface but multiple levels of meaning latent are peeled 
away, from which particular meaningful images are identified to be examined for their emotional consequences (Csordas, 2012), similar to what happens in epoche. According to Csordas (2012), each method emphasizes on collocating the "residue of consciousness and the baggage of experience" to reach an indispensable essence of experiential truth. Both phenomenology and psychoanalysis attend to the "most unique, private, and idiosyncratic moments that open up the universal human panorama and are ultimately reinserted either descriptively or therapeutically" into the live context it emerged from (Csordas, 2012).

However, according to Foucault (1986), Freud investigates only the semantic function of the dream, leaving its syntactic structure unnoticed. Freud was "unable to handle the relationship between meaning and image despite his analysis of the mediating functions of repression and fantasy." To Foucault (1986), Husserl could bring forth a theory of the symbol to successfully restore the "immanence of meaning to the image" by differentiating between the index elements of which the symbol is comprised and the signification of meaning which compose the dream experience from within the person. In addition to this, Phenomenology, unlike psychoanalysis, does not simply presuppose an instantaneous congruence between meaning and image rather observes their mutuality in the "expressive acts" and allows to recapture the meaning in the context of the expressive act, which found it (Binswanger et al., 1986). Psychoanalysis could not succeed in making images speak, while phenomenology could, but has given no prospect of understanding what the images say (Csordas, 2012).

The mode of understanding for phenomenology is the essence or eidos, not the "universal essence," but the "essence of the particular," not the universal essence of humanity but the particular essence of you or me as humans (Csordas, 2012). Psychoanalysis, as Csordas (2012) explains, is essentially related to intrapsychic development. With ongoing attempts to work out the underlying conflicts that ascertain that development, it can be said that the psychoanalytic concept of the complex is the counterpart of the phenomenological essence, 
embedded in the unconscious just as the essence is embedded in existence (Csordas, 2012). Moreover, like Phenomenology- where the search for the essence of a phenomenon is carried out using systematic reflection of something that is being experienced, the methodological procedure in Psychoanalysis also presupposes reflection, as the analyst reflects on the analysand's material and the analysand constituting a crucial moment in the psychoanalytic treatment. Etchegoyen (1991), a Kleinian psychoanalyst, has drawn similarities between the analysand's verbalization in the psychoanalytic process and Husserl's eidetic reduction (a methodological option that aims to go from the particular to the essential) describing the psychoanalytic process of receiving knowledge as an oscillation between a general narration of one's account, free association, and a greater degree of self-conscious reflection of one's experiences.

Phenomenology represents, in some sense, a suspension from the everyday, common-sense attitude, an attitude encapsulated by Husserl's expression 'the natural attitude'. In that, the world presents itself as being imbued with phenomena entirely independent of the discerning human being (Karlsson, 2010). Karlsson (2010) describes it as our spontaneous, uncritical, unreflective way of being in the world where the world seems as if already determined, and our experience as if caused by extrinsic, independent stimuli. It is this natural attitude that phenomenological reduction intends to breaks. This break with social everydayness is also signified by the free association in psychoanalysis, which makes it possible to get a hold of the unconscious, making it a subject for investigation in a way that is not possible in every day affairs. Thus, it is in account of this suspension in the everyday way of being in the world that it becomes likely to reveal hidden dimensions of our existence (Karlsson, 2010). Karlsson (2010) also added that both Phenomenology and Psychoanalysis are interested in the latent. In a sense that they are less concerned with that which is distinct, thematically conscious, but more with uncovering something beneath the surface. Nevertheless, the 
approach that psychoanalysis and phenomenology carry out to uncover latency differs. Phenomenology does it through reflections based on the subject's intending, and Psychoanalysis does it by approaching the unconscious (Karlsson, 2010).

However, phenomenologists like Maurice Merleau-Ponty and Jean-Paul Sartre were critical of the psychoanalytic idea of the unconscious. Merleau-Ponty considered the idea of the unconscious as 'idealistic,' in the sense that it suggested the unconscious as something transcendent, as something outside the world. According to him, there was nothing but the incarnated subject who is in the world. Sartre (1943) too objected to the idea of the unconscious, claiming that it is "logically impossible to postulate censorship whose character is such that it knows what to keep away from consciousness." Nevertheless, the unconscious in psychoanalysis, like existence in phenomenology, leaves a space open for life-long exploration as the questions of existence and unconscious may never be answered with certitude.

In Husserlian Phenomenology, the concept of intuition is an insight into the nature and meaning of something through the experience of that something. Eidetic reduction helps bring about an intuition into something as essence by employing a technique known as imaginative free variation (Ashworth \& Chung, 2010). In this, the phenomenologist centralizes the phenomenon of interest with as much spontaneity as can be gathered and condense it as far as feasible to its existential core. According to Crosdas (2012), the phenomenon is subjected in a way a stone might be studies, by turning it over and over, seeing it, feeling it from all workable angles. Crosdas (2012) further adds that it is at the intersection of all possible contexts and associations that the essence of the phenomenon is to be found, "to the point of testing the limits of reality and feasibility." These limits of reality and feasibility are of pressing emphasis in the psychoanalytic free association as it is the patient's grasp over reality and the emotional feasibility that are at stake in therapy (Csordas, 
2012). In this respect, "phenomenology engages the imagination while psychoanalysis taps the imaginary," where the goal of free variation is to "leave no stone unturned, and the potential drawback is lack of closure," the stance of free association is that something is being steered clear of, and the drawback could be a "foreclosure of meaning" (Csordas, 2012).

In phenomenology, to try to be as faithful to the phenomenon that we meet in as presuppositionless a way as possible is emphasized (Reed-Downing, 1990). Husserl's development of phenomenological reduction is to assure this openness. However, as usually known for its exclusion of deductive theorizing, Phenomenology does not, as is believed, exclude inferences, analogies, and the like, provided that they bring the investigator closer to what could, in the end, be directly grasped (Wertz, 1993). Psychoanalysis, likewise, in its investigation of the unconscious, is dependent on theoretical constructions, but it does not negate from trying to be as open and un-presupposing as possible in the psychoanalytic investigation (Winograd \& Davidovich, 2014). Phenomenology first starts off by describing a subject matter and then moves to methodically respond to the demands of that subject matter in all its precision and intricacies (Wertz, 1993), as emphasized in psychoanalytical therapy as well. That the psychoanalyst holds up a screen through which the analysand's narrative and portrayal is sieved, must be considered an outworn and a deprecatory account of psychoanalysis (Karlsson, 2010).

Lastly, Husserl's aim of philosophizing, as explicated by Zahavi (2003) does not only have a practical, ethical motivation but also a theoretical one. According to Zahavi (2003), Husserl's sense of phenomenological frame of mind is not an objective and dispassionate occupation but that of a personal and existential salience. For Husserl, the vitality lies in the endeavour to live a life of utmost self-responsibility, that is, base thoughts and actions on as much insight as possible. As pointed out by Karlsson (2010), Husserl's philosophical aim for 
philosophizing can doubtlessly be qualified as a reason for undertaking psychoanalysis as the essence of psychoanalysis also lies in the idea that the analysand's acquiring of selfknowledge will provide her/him the capacity to choose and acknowledge a total responsibility for her/his deeds and experiences (Karlsson, 2010).

\section{CONCLUSION}

Phenomenology and Psychoanalysis have been the subjects of a rich and complex analysis in the philosophical tradition. A phenomenological attitude towards an experience opens the possibility of encountering the nuanced quality of an experience. It sees the truth in experience, not by it being able to meet a normative reality of experience, but by experience in itself. The articulation of phenomenological principles in the areas of method, content, and approach offers a systematic specification of a viewpoint that has been adhered to in practice in Psychoanalysis but has not been explicitly recognized as such. This lack of foundational self-consciousness has led natural science psychology to misappropriate Psychoanalysis. Seemingly opposites, it is ultimately encountered that the most fundamental tenets of Freud's theory and the methods he used to investigate mental life are in principle and practice, phenomenological (Wertz, 1993), a convergence through which it is hoped that a dialogue is extended to the one that explores potential grounds for methodological alliances with the human sciences in general. 


\section{REFERENCES}

Ashworth, P., \& Chung, M. C. (2010). Phenomenology and Psychological Science: Historical and Philosophical Perspectives (History and Philosophy of Psychology) (Softcover reprint of hardcover 1st ed. 2006 ed.). Springer. https://doi.org/10.1007/978-0-387-33762-3.

Bakewell, S. (2017). At the Existentialist Café: Freedom, Being, and Apricot Cocktails with Jean-Paul Sartre, Simone de Beauvoir, Albert Camus, Martin Heidegger, Maurice Merleau-Ponty and Others. Other Press.

Binswanger, L. (1963). Dream and Existence. In Being-in-the-World. Pp. 222-249. New York: Basic Books.

Binswanger, L., Foucault, M., \& Hoeller, K. (1986). Dream and Existence (Studies in Existential Psychology \& Psychiatry) (First Edition). Review of Existential Psychology and Psychiatry.

Boss, M. (1963). Psychoanalysis and Daseinanalysis. New York: Basic Books.

Cohen, A. (2000). The Origins of Freud's Theory of the Unconscious: A Philosophical link. Psychoanalytische Perspectieven. Published. https://www.psychoanalytischeperspectieven.be/wp content/uploads/2012/10/Cohen.pdf.

Csordas, T. J. (2012). Psychoanalysis and Phenomenology. Ethos, 40(1), 54-74. https://doi.org/10.1111/j.1548-1352.2011.01231.x.

Etchegoyen, R. H. (1991). The fundamentals or psychoanalytic technique. London: Karnac Books 
Fonagy P. (2003). Psychoanalysis today. World psychiatry: official journal of the World Psychiatric Association (WPA), 2(2), 73-80.

https://www.ncbi.nlm.nih.gov/pmc/articles/PMC1525087/.

Freud, S., \& Strachey, J. (1976). The Complete Psychological Works of Sigmund Freud (1st ed.). W. W. Norton \& Company.

Gallagher, Shaun, \& Zahavi, D. (2019, May 23). Phenomenological Approaches to SelfConsciousness (Stanford Encyclopedia of Philosophy). Standard Encyclopedia of Philosphy. https://plato.stanford.edu/entries/self-consciousness-phenomenological/.

Gerson, M. J. (2017, November 23). Seven Benefits of Psychoanalysis. PsychStudies.Net. https://www.psychstudies.net/seven-benefits-psychoanalysis/

Hartmann, H. (1964). Understanding and explanation. New York: International University Press.

Karlsson, G. (2010). Psychoanalysis in a New Light (Translation ed.). Cambridge University Press.

Kung, G., Smith, D. W., \& McIntyre, R. (1988). Husserl and Intentionality: A Study of Mind, Meaning and Language. Noûs, 22(1), 158. https://doi.org/10.2307/2215565.

Lagache, D. (1963). Psychoanalysis. New York: Walker.

Merleau-Ponty, M., (1982-83) Phenomenology and Psychoanalysis: Preface to Hesnard's L'Oeuvre de Freud. Review of Existential Psychology and Psychiatry XVIII no. 1-3.

Merleau-Ponty, M., Landes, D., \& Carman, T. (2013). Phenomenology of Perception (1st ed.). Routledge. (Originally published 1945)

Reed-Downing, T. (1990). Husserl's Presuppositionless Philosophy. Research in Phenomenology, 20, 136-151. http://www.jstor.org/stable/24654457. 
Sartre, J. P. (1943). Being and nothingness. New York: Philosophical Library

Kelly, S. D. (2002). “Husserl and Phenomenology.” In The Blackwell Guide to Continental Philosophy, edited by Robert Solomon and D Blackwell, pp. 112-142. Oxford: Blackwell Publishers.

Sibi, K. J. (2020). Sigmund Freud and Psychoanalytic Theory. LangLit. Published. https://www.researchgate.net/publication/342610778 SIGMUND FREUD AND PS YCHOANALYTIC THEORY.

Spiegelberg, H. (1972). Phenomenology in Psychology and Psychiatry: A Historical Introduction (Studies in Phenomenology and Existential Philosophy) (1st ed.). Northwestern University Press.

Wertz, F. J. (1993). The Phenomenology of Sigmund Freud. Journal of Phenomenological Psychology, 24(2), 101-129. https://doi.org/10.1163/156916293x00099

Winograd, M. \& Davidovich, M. (2014). Freudian Psychoanalysis and Epistemology: Political Disputes. Recherches en psychanalyse, 1(1), 73a88a. https://doi.org/10.3917/rep.017.0073

Zahavi, D. (2003). Husserl's Phenomenology. Stanford, CA: Stanford University Press 